\title{
AS NARRATIVAS DOCENTES “INSCRITAS” NOS PARECERES DESCRITIVOS
} THE TEACHING NARRATIVES INSCRIBED IN THE DESCRIPTIVE OPINIONS LAS NARRATIVAS DOCENTES ‘INSCRITAS’ EN LOS PARECERES DESCRIPTIVOS

\author{
Edison Aran Nunes Krusser \\ Doutorando pela Universidade de Santa Cruz do Sul (UNISC) \\ earank@farrapo.com.br \\ Cláudio José de Oliveira \\ Universidade de Santa Cruz do Sul (UNISC) \\ Doutor Professor na Universidade de Santa Cruz do Sul \\ coliveir@unisc.br \\ Daiane Kipper \\ Doutorando pela Universidade de Santa Cruz do Sul (UNISC) \\ daianekipper@hotmail.com
}

\section{Resumo:}

Este artigo apresenta uma discussão com base nos resultados finais de uma pesquisa que objetivou problematizar narrativas docentes "inscritas" nos pareceres descritivos. A problemática que conduziu o presente estudo fundamentou-se na seguinte questão: Como os pareceres descritivos, entendidos como currículo, constituem os alunos e professores? A pesquisa é de cunho qualitativo e pautou-se na análise documental de pareceres descritivos elaborados por uma professora, referentes a alunos do ensino fundamental, em uma escola municipal no sul do Brasil. Na análise do material de pesquisa, os pareceres descritivos foram assumidos como narrativas, com base nos estudos de Larrosa (2002; 2015), apoiados nos Estudos Culturais em Stuart Hall. Para pensar na docência, a pesquisa seguiu os estudos de Oliveira (2009; 2010), de Fabris e Silva (2015) e de Corazza $(1995,2002)$. Com base na análise documental, o estudo inferiu a presença de uma docência inscrita nas narrativas advindas desse processo de produção cultural do sujeito e que se situa a partir de um lugar que se faz potente para a Educação: o currículo. Desta forma, acredita-se que tal processo implica a constituição do espaço e do tempo da Educação. Essa invenção do aluno, nas escritas dos pareceres descritivos, inventa também o professor em sua cambiante constituição docente. Conclui-se que o professor, ao emitir seu conhecimento a respeito do aluno, posicionando-o, nomeando-o, também está se anunciando no parecer. Logo, o professor, ao escrever pareceres descritivos, também se inscreve neles.

Palavras-chave: Educação. Currículo. Docência. Narrativa. Parecer Descritivo.

\begin{abstract}
:
This article presents a discussion based on the final results of a research that aimed to problematize teaching narratives inscribed in the descriptive opinions. The problem that led to the present study was based on the following question: How do descriptive opinions, understood as curriculum, constitute students and teachers? The research is qualitative and was based on the documentary analysis of descriptive opinions elaborated by a teacher, referring to elementary school students, in a local school in South of Brazil. In the analysis of the research material, the descriptive opinions were assumed as narratives based on the studies of Jorge Larrosa $(2002,2015)$, supported in the Cultural Studies in Stuart Hall. In order to think the teacher, the research followed the studies of Oliveira (2009; 2010), Fabris e Silva (2015) and Corazza (1995, 2002). Based on the documentary analysis the study inferred the presence of a teaching inscribed in the narratives coming from this process of cultural production of the subject and that is situated from a place that becomes powerful for education: The curriculum. In this way, it is believed that this process implies the constitution of space and in the time of Education. This invention of the student in the writings of descriptive opinions also invents the teacher in his teaching. It is concluded that the teacher in issuing his knowledge about the student, positioning, naming is also being announced in the opinion.
\end{abstract}

Keywords: Education. Curriculum. Teaching. Narrative. Descriptive School Reports.

Artigo recebido em abril 2018. Aprovado em maio de 2019.

Cad. Pesq., v. 26, n. 2, abr./jun., 2019. 


\section{Resumen:}

Este artículo presenta una discusión acerca de los resultados finales de una investigación que ha objetivado problematizar-as narrativas docentes 'inscritas' en los pareceres descriptivos. La problemática que ha conducido el presente estudio se ha fundamentado en la siguiente cuestión: ¿Cómo los pareceres descriptivos, entendidos como currículo, constituyen los alumnos y łos profesores? La investigación es de carácter cualitativo y se ha pautado en el análisis documental de los pareceres descriptivos elaborados por una profesora, con relación a los alumnos de la enseñanza primaria, en una escuela municipal del sur de Brasil. En el análisis del material de investigación, los informes descriptivos han sido asumidos como narrativas, con base en los estudios de Larrosa $(2002,2015)$, apoyados en los Estudios Culturales en Stuart Hall. Para pensar en la docencia, la investigación ha seguido los estudios de Oliveira (2009, 2010), Fabris y Silva (2015) y de Corazza (1995, 2002). Basándose en el análisis documental, el estudio infirió la presencia de una docencia, inscrita en las narrativas advenidas de ese proceso de producción cultural del sujeto y que se sitúa desde un lugar que se hace potente para la Educación: el currículo. De esta manera, se cree que tal proceso implica la constitución del espacio y en el tiempo de la Educación. Esa invención del alumno, la hace también el profesor con la escritura de los informes descriptivos, en su cambiante constitución docente. Se ha concluido que el profesor, al emitir su conocimiento a respecto del alumno, posicionándolo, nombrándolo, también está anunciándose en el parecer. Luego el profesor, al escribir los informes descriptivos, también se inscribe en ellos.

Palabras clave: Educación. Currículo. Docencia. Narrativa. Parecer descriptivo.

\section{PALAVRAS INICIAIS}

A escola se mostra tão previsível neste mundo cultural marcado pela dinamicidade imposta pelos povos que lhe habitam (alguém habitaria fora?), justamente pela enfática marca de imprevisibilidade da cultura. Trazemos uma preocupação com o enfoque cultural, seja ele local ou global, direcionado para ações e reações culturais em uma tentativa de aproximação e legitimação teórica aos Estudos Culturais. Stuart Hall (1997a, p. 10) afirma que "a cultura não é nada mais do que a soma de diferentes sistemas de classificação e diferentes formações discursivas aos quais a língua recorre a fim de dar significado às coisas".

Resistimos culturalmente em busca de respostas para o que acreditamos possa ser melhorado, independentemente do nosso nível de exigência. Assim, os "Estudos Culturais compreendem a pesquisa como sendo da ordem da criação, ou seja, como uma forma de significação que implica uma tomada de posição política. Tal concepção afasta qualquer ideia relativa à neutralidade do conhecimento [...]" (HILLESHEIM, 2009, p. 239-240). E, também, "devido ao amplo poder analítico e explicativo que o conceito de cultura adquiriu na teorização social" (HALL, 1997a, p. 1), configurando a cultura como um conjunto diferenciado de significados. Nessa perspectiva, os Estudos Culturais "da América Latina têm mergulhado nos processos e artefatos culturais de seus povos, na cotidianidade das suas práticas de significação, na contemporaneidade de um tempo em que as fronteiras entre o global e o local se relativizam, se interpenetram e se modificam" (COSTA; SILVEIRA; SOMMER, 2003, p. 48). Nesse sentido, neste trabalho entende-se os pareceres descritivos como um artefato cultural. Entre outras justificativas para tal afirmação, elencamos a contribuição como narrativa no procedimento relativo à avaliação escolar ora em pauta, em especial pelo seu processo social de produção, quando elaborado no intuito de dizer, de comunicar sua relação de currículo escolar com a sua importância para a construção cultural no meio educacional:

Acultura que os Estudos Culturais "estudam" tem menos a ver com os artefatos culturais em si mesmos (textos, obras de arte, mitos, valores, costumes, etc.) do que com os processos sociais de produção, distribuição e recepção desses artefatos. Ao mesmo tempo, os estudos culturais privilegiam o modo no qual os próprios atores sociais se apropriam desses imaginários e os integram a formas locais de conhecimento. (COSTA; SILVEIRA; SOMMER, 2003, p. 52).

A temática da avaliação é parte incontornável para pensarmos o processo educacional e para estabelecermos certa distância com o tema, que inspira controle, 
regulação e disciplinamento das condutas que são anunciadas nos pareceres, e quando pensamos em dizer Narrativa logo quisemos colar, estabelecer uma ligação, dar um cheiro de Cultura à uma maneira de dizer. Nessa mesma esteira do pensamento, Thoma (2009, p. 49) compreende a avaliação como um mecanismo de controle, regulação e disciplinamento dos outros e de nós mesmos, e os procedimentos e instrumentos que utiliza são governo de condutas.

Neste trabalho, estamos compreendendo avaliação, currículo, narrativas, como artefatos no campo dos estudos culturais no que tange à invenção de pessoas/produção de sujeitos (professores, alunos) e coisas que lhes acontecem. Nessa perspectiva teórica, o presente estudo problematiza as narrativas docentes 'inscritas' nos pareceres descritivos. Para isso, a problemática que conduziu o presente estudo pautou-se na seguinte questão: Como os pareceres descritivos, entendidos como currículo, constituem os alunos e professores?

A pesquisa é de cunho qualitativo e pautou-se na análise documental de pareceres descritivos elaborados por uma professora, referentes a alunos do ensino fundamental, em uma escola municipal no sul do Brasil. Foram analisados trinta e dois pareceres de oito alunos de uma turma de $2^{\circ}$ ano do ensino fundamental referentes a quatro bimestres do ano letivo de 2014. A análise documental desses pareceres ocorreu no ano de 2015. Como pensamos em contar/compartilhar este trabalho através de recortes que consideramos um tanto mais apropriados didaticamente para a compreensão de tal relato, no presente artigo, nos pautamos nos pareceres descritivos referentes ao primeiro bimestre letivo de 2014 da escola em que a pesquisa ocorreu. Logo, esses pareceres apresentam-se como um recorte do material empírico com o qual conversamos. Os aludidos representantes desses documentos fazem-se acionadores de um gatilho para iniciarmos a caminhada pelo presente estudo, visto que é desde esse desejo de vêlos em suas possíveis nuances que pensamos analisá-los metodologicamente, numa perspectiva que visa tocar suas propriedades comunicativas ali contextualizadas. Ao longo de tal caminhada, buscamos dialogar com o que é dito, sobre quem é dito (aluno), com quem diz (docente) e sobre como isso poderá ou não ser constituidor na feitura de um parecer descritivo e suas condições de possibilidade para conversarmos com o meio educacional.

Com base nos pressupostos teóricos e nos pareceres descritivos que embasam as discussões do presente estudo, apresenta-se sua organização em cinco seções: na primeira, intitulada As palavras inicias, apresentamos o objetivo, o problema, o recorte empírico da pesquisa e as questões teóricas que embasam o presente estudo; na segunda seção nomeada a Imprevisibilidade da cultura e do currículo apresentamos questões sobre cultura e currículo com base na perspectiva dos Estudos Culturais; a terceira seção, Parecer descritivo como artefato cultural, está pautada no currículo como um artefato cultural que tem a função de incutir normas; a quarta seção, Discussão dos resultados, está composta pela análise da empiria da pesquisa; a quinta seção, 'Parecer', final apresenta nossa conclusão com base no objetivo da pesquisa; e, por fim, citamos as referências que embasam as discussões.

\section{IMPREVISIBILIDADE DA CULTURA E DO CURRÍCULO}

Posicionamo-nos, assim, como educadores que pesquisam em tal meio. Para tanto, defendemos que está intrínseca na função do educador, a possibilidade de situarse em uma Matriz Pedagógica Escolar, entendida como "uma grade de inteligibilidade que regula as ações docentes e a vida escolar dos alunos em um determinado tempo e espaço" (FABRIS; SILVA, 2015, p. 493) capaz de, sob nossa perspectiva, oportunizar conhecimentos que viabilizem, entre outras coisas, qualidade de vida minimamente sustentável ao educando em seu tempo, ante um espaço que também se faz forma na educação. O que seria do relato sobre uma experiência se não houvesse a curiosidade e a pesquisa em fontes que tratam historicamente do assunto? Afinal, Larrosa, em Tremores (2015, p. 40), salienta que "a experiência é sempre de alguém, subjetiva, é

Cad. Pesq., São Luís, v. 26, n. 2, p. 29-46, abr./jun., 2019. 
sempre daqui e de agora, contextual, finita, provisória, sensível, mortal, de carne e osso, como a própria vida". Para o autor, a experiência é a desordem e a indecisão da vida.

Assim experimentamos a aproximação aos pareceres descritivos como dispositivos que permeiam e se fazem instrumentos de comunicação de resultados obtidos durante o processo de avaliação, desde as percepções advindas de atividades que conotam mudanças de comportamento nos alunos que habitam a escola e são tocados pelo processo de ensino e aprendizagem. Esta escola que é amiga, acolhedora, preparada para compartilhar conhecimentos e que tem a missão de ensinar a pensar. Somos deste chão de escola, que habitamos e onde laboramos, "é o habitat ou espaço [...] que oferece as condições para o desenvolvimento de um ethos filosófico como um ethos atento e experimental e, em certo sentido, para a captura do que está acontecendo hoje" (MASSCHELEIN, 2014, p. 22).

Este é um início destinado a contribuir com a investigação que constitui este trabalho. Junto com Foucault, que "ao invés de tomar a palavra, gostaria de ser envolvido por ela e levado bem além de todo começo possível" (FOUCAULT, 1998, p. 5) queremos falar sobre o que desejamos falar. Dizer tudo que nos ocorre sobre o assunto, mas não "falar muito e não dizer nada", que é uma frase inspiradora proferida por Veiga-Neto, durante palestra no $X$ Seminário Nacional de Pesquisa em Educação (SEPEDU), na Universidade de Santa Cruz do Sul (UNISC) em 2014. Como não cair nesta prática? Temos que dizer já. E sermos tão claros quanto possível, para conversarmos acerca de pareceres descritivos como narrativas a serviço da avaliação:

\begin{abstract}
Uma conversa não é algo que se faça, mas algo no que se entra... e, ao entrar nela, pode-se ir aonde não havia sido previsto... e essa é a maravilha da conversa... que, nela, pode-se chegar a dizer o que não queria dizer, o que não sabia dizer, o que não podia dizer. (LARROSA, 2003, p. 211).
\end{abstract}

Nesse mesmo sentido, Pereira (2013, p. 214) lembra que "a palavra faz existir. Só existe aquilo que se pode dizer, como em um arremedo da criação divina. A palavra é o cerne da linguagem, e a linguagem é a casa do ser. [...] sempre produz efeitos de verdade". Para poder ver de outra maneira: "Ao analisar os discursos, [...] extraindo enunciados, mostrando suas regularidades, apontando para a instituição de um determinado modo de ser professor, de pensar sua própria prática, é preciso também buscar os silêncios" (OLIVEIRA, 2009, p. 187, grifo nosso). Alertamo-nos para as inúmeras nuances que podem ser consideradas para tal leitura e é dessas sutilezas cambiantes, desses silêncios, que buscamos apropriação.

Segundo Fröhlich (2010, p. 71-72), os pareceres descritivos são, de alguma forma, uma maneira de prescrever após

[...] uma rigorosa observação do aluno nas diferentes situações e momentos de aula e da escola para que, baseados na descrição desta observação e na constatação de alguns 'sintomas', possa ser prescrito um tratamento adequado às suas características e manifestações [...].

Dessa forma, falamos, entre outras coisas, de como se constitui essa capacidade de dizer o que se vê, se detecta. Não somente o que foi dito, mas como se dá essa capacidade de dizer, desde a concepção adotada pelo parecerista e suas expectativas e perspectivas (ex)postas no documento. Tais documentos:

Se caracterizados de forma breve, consistem uma ficha individual, preenchida com dados sobre o desempenho escolar de cada aluno e aluna. Não são considerados "instrumentos de avaliação" (como as provas, testes, exames), mas alinham-se na mesma categoria do Boletim Escolar, isto é, como "instrumentos de expressão dos resultados da avaliação", podendo fazer parte do próprio texto do Boletim, ou vir anexados a ele, em uma folha à parte. (CORAZZA, 1995, p. 48). 
Talvez desde sempre, neste trabalho, estivéssemos em busca do encontro com o professor: esse ser que de acordo com Veiga-Neto (2012), precisa "habitar" sótãos e porões para autorizar-se a caminhar pelos cômodos intermediários da educação (que ele busca conhecer, para conhecer-se). Se ficarmos presos nos andares intermediários, "sem habitar o sótão e o porão, perderemos boa parte de nossa própria condição humana, pois, enquanto lá no sótão se dão as experiências da imaginação e da sublimação, é lá no porão que estão as raízes e a sustentação racional da própria casa" (VEIGA-NETO, 2012, p. 269).

Na perspectiva pós-estruturalista "não há verdades absolutas e únicas, as verdades são sempre produzidas nas relações de poder entre as pessoas. As verdades, nesse sentido, são sempre circunscritas e históricas" (FÉLIX, 2014, p. 137-138). Na educação, poucos "descem aos fundamentos nos quais se enraízam suas opções epistemológicas e, consequentemente, poucos conhecem o subsolo em que se alimentam suas convicções acerca da salvação por obra da educação" (VEIGA-NETO, 2012, p. 276). E, ao não descer aos porões, a maioria não problematiza as verdades tidas como naturais no campo da educação. Nesse sentido os Estudos Culturais em sua interlocução com a educação, se apresenta como um

[...] campo homogêneo e em sua própria definição se colocam como interdisciplinares, contradisciplinares, ou até mesmo não disciplinares, sendo que partem de diferentes saberes para problematizar as questões relativas à cultura. [...] o ponto central encontra-se em uma nova forma de reconhecer e situar a cultura, reconhecendo que não existe um lócus privilegiado que sirva de ponto de partida unívoco para 0 conhecimento. (SILVA, M., 2009, p. 7).

Arriscamo-nos pelo terreno da teorização e problematização cultural e suas nomeações nas diversas possibilidades de sentido, dos domínios tradicionais elitistas ao gosto popular (das multidões), que constituem a atual e diversificada indústria cultural contemporânea através, também, de palavras que nomeiam discursivamente. Como diz Costa, Silveira e Sommer (2003, p. 37) as palavras

[...] têm história, vibram, vivem, produzem sentidos, ao mesmo tempo em que vão incorporando nuanças, flexionadas nas arenas políticas em que o significado é negociado e renegociado, permanentemente, em lutas que se travam no campo do simbólico e do discursivo.

Assim, desde essa negociação, é possível afirmarmos que só existe o que é nomeado e para nomear precisamos ter visto, pois, conforme Larrosa (2002, p. 21):

\footnotetext{
quando fazemos coisas com as palavras, do que se trata é de como damos sentido ao que somos e ao que nos acontece, de como correlacionamos as palavras e as coisas, de como nomeamos o que vemos ou o que sentimos e de como vemos ou sentimos o que nomeamos.
}

Como podemos saber se o que pensamos já não foi pensado, dito e escrito em algum outro lugar ou tempo? Não que desejemos o ineditismo, mas por não desejarmos o perigo da cópia, que conforme Silva M. (2014, p. 17) "é o símbolo maior da nossa mediocridade individual". Essa mediocridade é aproximadora ao tempo do refugo. Escolhemos falar um pouco do tempo, agora. Enquanto (sempre) flui. Das possibilidades do sucesso e do fracasso ante ele: "se a vida pré-moderna era uma recitação diária da duração infinita de todas as coisas, com exceção da existência mortal, a vida líquidomoderna é uma recitação diária da transitoriedade universal” (BAUMAN, 2005, p. 120).

A educação, nesse tempo, é um universo de entrelaçamentos e malhas indizíveis, tal é a sua abrangência, sua capacidade espiral de energia e potência, em um universo que produz cultura, subjetivações e demanda relações de poder permeadas, atravessadas por disputas de interesses diversos, que por sua vez geram conflitos, os quais precisam acionar mecanismos de controle e organização para regular tais interesses, que se fazem políticos no campo cultural educacional. Assim, o currículo 
escolar é também uma produção cultural, visto que ele é "[...] produzido na cultura e, por sua vez, produz sentidos, colocando-os em circulação, constituindo os sujeitos escolares. São essas práticas que considero importantes para problematizar na significação das aprendizagens escolares e na produção das subjetividades" (FABRIS, 2007, p. 5).

Nessa produção de subjetividades situa-se a escrita dos pareceres descritivos, visto que ao avaliar, há também o controle, a regulação e o disciplinamento de si. Para Thoma (2009, p. 52) o processo (de avaliação) "não se dá, obviamente de uma forma tranquila, e por isso a escola e a pedagogia buscam formas de avaliar que determinem o mais precisamente possível se (e o quanto) um aluno e seu conhecimento são válidos".

Nessa esteira do pensamento, Hall (1997b, p. 6) defende que:

os sujeitos são inventados através de vários significados, ideias e versões de mundo que possuem. Os discursos constroem significados, valores, crenças e emergem de visões particulares, de modos de agir e de pensar sobre o mundo. Sendo práticas sociais, implicam relações de poder.

Essa cultura escolar traz o tempero com sabor pedagógico, de educação, o que lhe caracteriza sobremaneira, em especial nesta contemporaneidade que abriga a escola, sua pedagogia oniforme (que, por vezes, assume, toma ou é tomada, por todas as formas, ou, nenhuma), suas representações midiáticas deste mundo e suas condições de possibilidade para conceitualizar o currículo que inventamos:

Currículo cultural diz respeito às representações de mundo, de sociedade, do eu,
que a mídia e outras maquinarias produzem e colocam em circulação, o conjunto de
saberes, valores, formas de ver e de conhecer que está sendo ensinado por elas.
Pedagogia da mídia refere-se à prática cultural que vem sendo problematizada para
ressaltar essa dimensão formativa dos artefatos de comunicação e informação na
vida contemporânea, com efeitos na política cultural que ultrapassam e/ou produzem
as barreiras de classe, gênero sexual, modo de vida, etnia e tantas outras. (COSTA;
SILVEIRA; SOMMER, 2003, p. 57).

Assim, somos atravessados por essas questões culturais que se fazem presentes no dia a dia do ambiente educacional, em seus diversos e cambiantes espaços e tempos que, por vezes, influenciam e interagem com e nesta contemporaneidade. Na perspectiva dos Estudos Culturais em suas interlocuções com a educação, "encontramos subsídios para afirmar que a educação se dá em diferentes espaços do mundo contemporâneo, sendo a escola apenas um deles. Quer dizer, somos também educados por imagens, filmes, textos escritos, pela propaganda, pelas charges, pelos jornais e pela televisão" (COSTA; SILVEIRA; SOMMER, 2003, p. 57), ou seja, por artefatos que se expõem em nosso cotidiano diariamente que são nomeados pelos referidos autores como currículo cultural. Tendo em vista a disseminação de informações acerca do que acontece neste mundo, dito globalizado, pela latente instantaneidade na divulgação de suas ações.

Parece-nos apropriado para este momento e de uma maneira geral para a concepção de todo este texto que falemos sobre a questão das fakenews (notícias constituídas de "invencionices" ou criações fantasiosas e por vezes criminosas que distorcem a realidade com algum intuito escuso). Embora elas sejam fruto de uma construção cultural, também por isso precisam ser pensadas e descritas em sua existência.

Ainda, a invenção que referimos em nosso trabalho alude uma ideia de criação, construção, constituição de uma realidade possível, afastando-se, portanto, da concepção fraudulenta que o termo possa dar entendimento. Então, torna-se ainda mais importante, em termos de responsabilidade, a disseminação do conhecimento que é compartilhado na escola (leia-se: Currículo escolar), através de técnicas didáticas e por docentes que estejam cientes dessas questões. 
Destes cruzamentos que nos ocupamos para abordarmos educação e pedagogia numa perspectiva cultural no mundo contemporâneo e que tem como ambiente central a escola, que também traz como missão a difusão das múltiplas visões desde esse mundo. Um contexto habitado por usuários (em especial, nossos alunos) da internet, que acessam conteúdos, que produzem seus próprios currículos, oportunamente descrito por Jeane Félix, falando dessa rede mundial de computadores em que "nela, jogam, estudam, namoram, fazem sexo, escrevem, postam fotos/desenhos/imagens, encontram e conhecem amigos e amigas, tornam-se outras e muitas pessoas, além de infinitas possibilidades" (FÉLIX, 2014, p. 135, grifos da autora). Na escola, quais seriam esses conteúdos, que não lhe são tão atraentes, que concorrem com os vindos pela internet? A reinvenção da educação, que se dá diariamente, não poderia utilizar-se mais fortemente dessa ferramenta midiática para uma construção otimizada desde essa concepção de mundo mutante na palma da mão?

Pensamos (não como uma mera opção, mas talvez para uma conversa) recorrer, também, e recorremos, a uma ferramenta que nos ajuda a significar o mundo: a linguagem, como diz Gustsack (2008, p. 1): "Tomo a linguagem como manifestação do humano em seu devir". Nessa perspectiva, estamos compreendendo a docência também como uma narrativa que se "inscreve" na escrita sobre o aluno nos pareceres descritivos.

Dessa forma,

talvez, em nenhum outro domínio da prática escolar, a política cultural para a constituição da infância-escolar contemporânea possa estar tão explicitamente demonstrada e operante quanto no sistema de elaboração e divulgação dos pareceres. Pois, onde encontrar outro dispositivo escolar-cultural, a tal ponto eficiente e eficaz, que, quase ao mesmo tempo, consiga: a) enunciar o que é e o que deve ser um sujeito (e, portanto, também o que ele não é, nem deve ser); b) cuja ressonância seja tão diretamente imediata no grupo social e no próprio sujeito "descrito"; c) estar fortalecida por padrões absolutos de notas e conceitos, acrescidos do julgamento de aprovado/reprovado, que apontam para os destinos sociais daquele mesmo sujeito? (CORAZZA, 1995, p. 49).

Vemos nos pareceres descritivos um artefato cultural, incutindo normas, padrões e valores, o que caracteriza a cultura, segundo Stuart Hall (1997a), em virtude da identificação da existência de pedagogia, modos de ensinar e possibilidades de aprendizagem em suas diversas constituições: o docente falando de um aluno no contexto educacional, onde tudo e nada pode acontecer. Mas, que mesmo o nada seja tudo para esta pesquisa, colocada em um lugar que atue nos autorizando a não termos certeza, mas a problematizarmos tais questões.

Dispusemos as seções deste trabalho, pensando no conforto do leitor para melhor apreciar esta caminhada, desde o nosso caminhar. Os pareceres descritivos se apresentam, nessa pesquisa, como uma possibilidade para serem problematizados e por sua vez desnaturalizados. Logo, trazem consigo a imprevisibilidade da cultura, o currículo. Falam na escola que lhes produz desde a constituição de uma docência atravessada por (auto)conhecimentos. Metodologicamente inquirem, esmiúçam sua função na avaliação, embasam-se em jurisprudências. Trazem invenções, categorizações. Focalizam, apontam possibilidades. Narram discentes e anunciam condição docente em tais narrativas. Fabricam continuidades e descontinuidades.

\section{PARECER DESCRITIVO COMO ARTEFATO CULTURAL}

Apresentamos uma ferramenta midiática (termo apropriado pelos Estudos Culturais) e que representa uma vontade de transgressão visual comunicativa para trazer os documentos de que nos ocupamos nesta pesquisa. Referimo-nos a imagem, elaborada no Wordle-Create, ilustrada abaixo: 


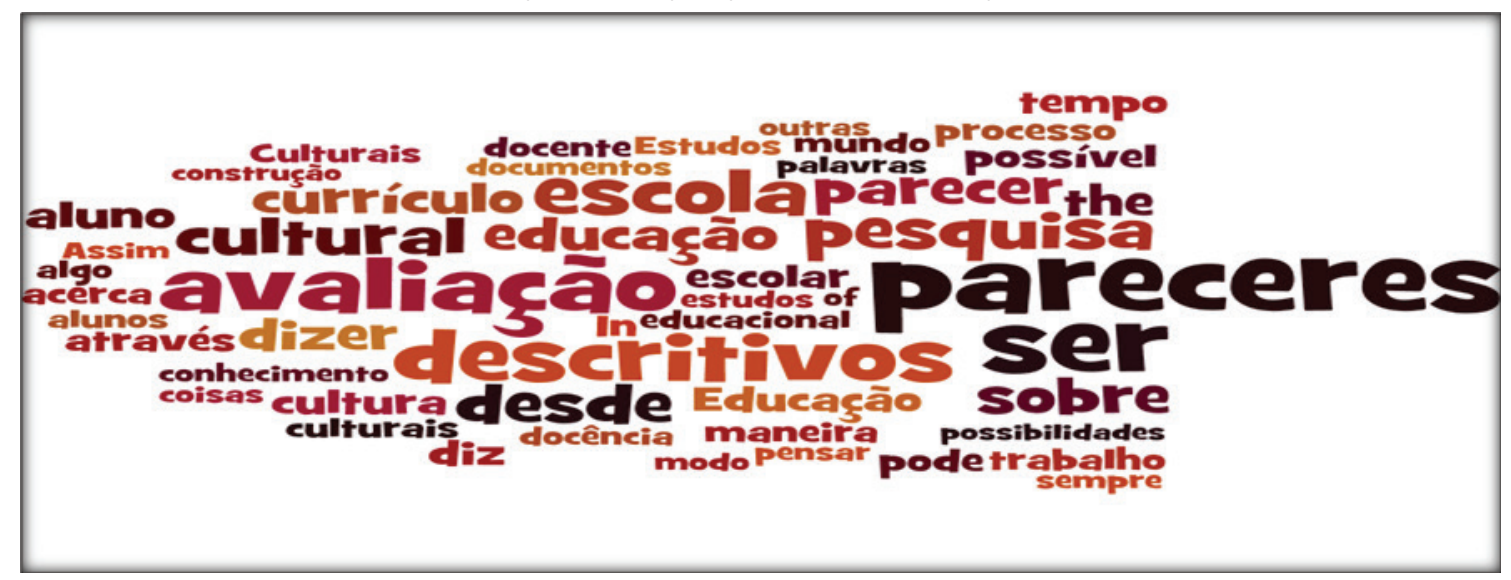

Fonte: Elaborado pelos autores.

Conforme a definição do Wordle-Create, em suas informações adicionais, o referido programa é um 'brinquedo' para gerar 'nuvens de palavras' do texto fornecido ao ambiente. As nuvens dão maior destaque às palavras que aparecem com mais frequência no texto de origem. A imagem acima foi gerada utilizando o texto total deste artigo. Optamos por essa demonstração para exemplificar o procedimento que adotamos para ver os pareceres descritivos, durante a análise do material empírico e que traz, desta vez, as cinquenta palavras mais recorrentes. Esta é a característica principal desta ferramenta: indicar quais e quantas palavras são mais citadas no texto escolhido, conforme critério que se julgar conveniente, e que podem auxiliar-nos na análise das palavras mais citadas em documentos ou textos.

Um parecer que pode dizer todo o ano de um aluno. Uma escrita sutil que pode dizer de forma grafada padrões e ordens tidas como naturais. Maneira burocrática de apresentar um olhar pautado em questões culturais:

os documentos devem ser vistos como uma forma de contextualização da informação. Em vez de usá-los como 'contêineres de informação', devem ser vistos e analisados como dispositivos comunicativos metodologicamente desenvolvidos na construção de versões sobre eventos. (FLICK, 2009, p. 234).

Assim, utilizamos o preceito de criação, invenção, multiplicação, proliferação, contágio, pois

existem muitas entradas para as pesquisas pós-críticas em educação e em currículo. Podemos adentrar nesse território por diferentes trajetos, desde que observadas algumas precauções necessárias. Gostamos muito de entrar nesse território pelo caminho da expansão, e percorrer a sua força de proliferação. Isso porque acreditamos no potencial dessas pesquisas para desarrumar e desmontar o que já foi pensado na educação e, a partir daí, criar, inventar, multiplicar, proliferar, contagiar...Acreditamos que é possível traçar possibilidades de - na pesquisa em educação e currículo encontrarmos estratégias para fugir dos sistemas de pensamento que thes dão base e abrir os corpos para outras imagens de pensamento. (PARAíso, 2014, p. 44).

Trazemos esta ideia de pesquisa pós-crítica, justamente pela sua maneira contemporânea de ver a cultura, através da leitura do conhecimento e do currículo em um campo que desacomoda e possibilita construções e desconstruções de concepções e interpretações e que se proliferam em invenções e criações desde o pensamento. Tais conhecimentos, que trazem toda esta gama de possibilidades, não escapam ao esquadrinhamento da avaliação e suas possibilidades de ver.

Hoffmann (2009) afirma que avaliar é uma tarefa e que, portanto, precisa ser movida por finalidades/intencionalidades claras por parte do educador. Nesse sentido, "[...] a finalidade das tarefas é o que irá determinar os rumos da intervenção pedagógica 
(a mediação). Mais importante do que as tarefas que o aluno faz é o que o educador faz a partir das tarefas que ele fez (e que o educador analisou)" (HOFFMANN, 2009, p. 69).

Trazemos documentos que são embasadores, ordenadores indispensáveis para o funcionamento de uma escola. Um documento legal que apresenta o direcionamento, a normatização que organiza a administração, os aspectos pedagógicos e disciplinares, e as relações peculiares aos diversos aspectos constitutivos, é o Regimento Escolar, que entre outras coisas, normatiza as avaliações concernentes ao resultado anual aferido pela média aritmética dos bimestres (períodos de dois meses em que é dividido, compartimentado, o ano letivo para, entre outras medidas, ser efetivada a aferição da caminhada educacional. Tal divisão pode ser variável em relação ao número de meses) e do sistema de recuperação para os alunos que não alcançarem o mínimo de aproveitamento.

Deste documento, mesmo que aborde todos esses passos organizacionais, nos valeremos especialmente, do componente que trata da avaliação da aprendizagem. Este, dita procedimentos de avaliação como um processo abrangente que envolve não só a aprendizagem do aluno, como também a prática do professor. Portanto é constituidor desses atores. Diz também que nesta etapa do planejamento o professor avalia todo o processo educativo para confirmar ou redimensionar a sua programação, as relações que se dão em aula e a escola na sua dinamicidade, com a pretensão de tornar viáveis as estratégias pedagógicas adequadas à promoção do sucesso escolar, sempre dando prioridade aos aspectos qualitativos em relação aos quantitativos.

Com a contribuição de Luckesi, podemos notar considerações acerca de avaliação e exame, dos termos qualitativo e quantitativo nesse campo, que podem servir para uma conversa embasadora quando a ideia for relacionada à discussão do movimento de avaliar e suas implicações:

Avaliar é o ato de diagnosticar uma experiência, tendo em vista reorientá-la para
produzir o melhor resultado possível; por isso, não é classificatória nem seletiva, ao
contrário, é diagnóstica e inclusiva. O ato de examinar, por outro lado, é classificatório
e seletivo e, por isso mesmo, excludente, já que não se destina à construção do
melhor resultado possível; tem a ver, sim, com a classificação estática do que é
examinado. O ato de avaliar tem seu foco na construção dos melhores resultados
possíveis, enquanto o ato de examinar está centrado no julgamento de aprovação ou
reprovação. (LUCKESI, 2002, p. 5).

É disto que falamos quando pensamos em uma possível 'conversão' de números (quantitativo) em pareceres descritivos (qualitativo), dentro da prática docente, no que concerne à avaliação. Mas, de algum modo, reverenciamos este acontecimento como mais uma maneira de vislumbrar a prática desse docente que paira em nossa visão, elaborando tais pareceres desde tais normatizações e regulamentações. A avaliação para ser avaliação, deve ser sempre qualitativa. Logo, avaliar é atribuir qualidade a alguma experiência ou situação (LUCKESI, 2002).

Parece-nos interessante pensarmos em emitir juízo de qualidade acerca da ideia de avaliação, embasada em uma gama de possibilidades de instrumentos de medição/ mediação, numa perspectiva de quantidade, de recorrências, aferições que trazem resultados para serem traduzidos como qualidade a ser dita em seu patamar. O parecer descritivo relata essa qualidade. Para regular, regulamentar, controlar, vigiar todo esse aparato avaliativo, cria-se documentos que buscam legitimar tal processo, no espaço e no tempo educativo.

Os pareceres descritivos estão na ordem do discurso da educação. Da educação infantil ao $3^{\circ}$ ano do ensino fundamental (dependendo do Regimento da escola), as avaliações, em sua maioria, se pautam na escrita dos pareceres descritivos. Entretanto, sua prática de escrita entre os docentes tem sido pouco problematizada nas escolas. Onde estariam os porões dos pareceres descritivos? Veiga-Neto (2012, p. 491) que em seu texto É Preciso ir aos Porões se pauta na metáfora bachelardiana que apresenta a 
casa como nossa primeira morada no mundo e argumenta que "a favor da necessidade de conhecermos os porões e alicerces arquetípicos e epistemológicos que sustentam as nossas práticas educacionais cotidianas e dão sentido a elas".

Dentre os discursos que legitimam a escrita dos pareceres, está o Regimento escolar que por sua vez se apresenta como um documento que embasa o Plano PolíticoPedagógico (PPP) da escola. Lançamos mão dos estudos da professora Veiga (1998) que, por sua vez, apoia-se em autores como Pedro Demo, Moacir Gadotti, Henry Giroux, Dermeval Saviani, entre outros, para compreendermos o PPP e suas implicações no âmbito educacional escolar.

O PPP é uma ruptura com o presente, com o posto, e que busca através do planejamento uma inserção, uma projeção identitária no futuro, para acompanhar a dinamicidade da vontade de qualidade da dimensão política de inferir na sociedade a formação otimizada e democrática do cidadão através, também, da contribuição da técnica, da metodologia e da prática pedagógica, que se faz necessariamente recíproca e que resulte em ações educativas constitutivas da história desse cidadão, no e em prol de seu meio escolar possível, autônomo, reflexivo e globalizado. "O projeto políticopedagógico, ao se constituir em processo democrático de decisões, preocupa-se em instaurar uma forma de organização do trabalho pedagógico que supere os conflitos" (VEIGA, 1998, p. 12), com o objetivo de eliminar a competividade e assim diminuir a hierarquia entre poderes.

Por sua vez, a Lei de Diretrizes e Bases da Educação Nacional (LDB) revela uma exigência democrática, ao propor uma expressão de autonomia da escola na construção de proposta pedagógica que proporcione exercício de cidadania através da articulação das experiências educacionais com a realidade enfrentada pela sociedade atual. Nos documentos do Pacto Nacional pela Alfabetização na Idade Certa (PNAIC) encontramos uma ideia de política pública que traz em especial, indicações de como proceder durante o processo de avaliação e elaboração de tomada de decisões a respeito da construção ou não de determinados avanços na constituição da aprendizagem do avaliado.

Nessa esteira do pensamento, as políticas públicas se apresentam como produtoras e produzidas por discursos que circulam no campo da educação. Pode ser interessante pensar os modelos de abordagem de questões como a avaliação dita pelos pareceres descritivos de uma maneira que pode representar um modo quase matemático, quase quantitativo, aproximado ao 'exato', linear, para avaliar através de não números, mas, que observa os mesmos termos para todos os alunos, com a variável de estar ou não adequados à afirmativa (por vezes negativa ou, que por vezes, nega). Com base nessas questões, na próxima seção, passamos a problematizar excertos dos pareceres descritivos.

\section{DISCUSSÃO DOS RESULTADOS}

Defendemos que não há uma 'receita' para a fabricação de pareceres descritivos, pois e ela constitui-se basicamente pela própria inexistência. O pior caminho pode ser o uso de caminhos conhecidos, caminhados, em que se diz a mesma ou similar coisa sobre diferentes. A afirmação que nega a homogeneidade pode ser um caminho razoável para a tentativa de se dizer algo de algo ou alguém que se produz e se instala em um coletivo. A capacidade de observação, em um diagnóstico, em dado momento, parece conversar com a possibilidade de aproximação à elaboração de uma narrativa padronizada por parte do docente.

A 'receita' é não ter uma. Não seguir uma. Não copiar sequer a mais recente e jamais criada. E criar aceitando e negando a proposição da pré-existência, de um já constituído, dado, (nem seguir esta!). Logo, não há 'receitas' para a escrita de pareceres, mas sim padrões e normas postas nas narrativas em torno das singularidades descritas. Para Masschelein (2014, p. 21) "a filosofia da/como educação, então, é tentar mais uma vez as palavras e os verbos, a fim de expô-los para que eles possam começar de novo 
a significar algo ou falar de algo". Um pesquisador que ao investigar o outro, também inventa a si mesmo. Hacking (2009 apud FABRIS; SILVA, 2015, p. 500), ao trazer a ideia de invenção de pessoas, afirma que "categorias de pessoas passam a existir na mesma hora em que tipos de pessoas passam a existir de modo a se encaixar nessas categorias, e há uma interação de mão dupla entre esses processos". Fabris e Silva (2015) nos proporcionam pensar na invenção de pessoas a partir de um movimento que entende a linguagem não apenas como representativa, mas como constitutiva da realidade.

Quando Oliveira (2010) se propôs a desenvolver etapas de um processo pedagógico que consistia em investigar de que modo a matemática estava presente nos afazeres da comunidade escolar, disse que "o movimento de reunir as mães e os pais, as atividades de tabulação de dados, os argumentos discutidos com e entre os estudantes, também foi considerado como parte do trabalho, como parte do currículo escolar de matemática" (OLIVEIRA, 2010, p. 243, grifo nosso). Este argumento nos autoriza, entre outras coisas, a vermos a dimensão possível da constituição do currículo e também a docência ali inscrita.

Ao fazermos uma busca nos arquivos do computador da secretaria da escola, pensando encontrar nesse compartimento alguma referência ligada ao interesse de pesquisa, localizamos um documento com a impressão do nome da professora Corazza. Uma citação que dava continuação ao título Pareceres Descritivos na qual constava que eram documentos que "[...] têm por propósito aparente comunicar, aos pais ou responsáveis pela criança, os progressos e as dificuldades individuais, fornecem sugestões de como melhorar e registrar os resultados parciais/finais do processo de aprendizagem da criança" (CORAZZA, 1995, p. 48).

Assim, o parecer dito pelo professor diz de si, diz o aluno, a escola, portanto o currículo compreendido como um conjunto de atitudes, valores e comportamentos que são 'ensinados' através das relações sociais, das práticas e da configuração espacial e temporal da escola (SILVA, T., 2000). Elencamos a seguir algumas questões e ou situações que estiveram presentes em nossos pensamentos e que se fizeram constituidoras desse pensar. A entrada da pesquisa, a escolha do tema, como ele nos afetou, nossa sensação de incompletude, a relação dos pareceres com a avaliação e seus entrelaçamentos no currículo. Dentre outras percepções a óbvia (ou não?) existência da docência que diz seus alunos. Aqui, por esta vez, trazemos também uma percepção de docência que se diz. Quem é, onde está, que lugar ocupa esse que descreve, que narra, desde a docência, na perspectiva pedagógica.

Para isso, apresentamos a seguir excertos dos pareceres referentes ao $1^{\circ}$ bimestre letivo de 2014, da escola pesquisada. Para preservar a identidade dos alunos, optamos pelo seguinte código para nomeá-los: utilizamos a letra "A" para as meninas, da letra "B" para os meninos. Sendo que a turma é composta por 2 meninas e 6 meninos, logo a numeração indica a ordem alfabética de cada gênero. Assim, os pareceres receberam os seguintes códigos: A1, A2, B1, B2, B3, B4, B5 e B6. Na pesquisa inicial, os bimestres (cada dois meses, dos oito letivos, complementados por recortes que invadem seus limites para oportunizar o total de duzentos dias letivos mínimos, regulamentares) são elencados e separados em cabeçalhos indicativos de qual período ordinal contempla (do $1^{\circ}$ ao $4^{\circ}$ ), entretanto aqui nos deteremos aos pareceres referentes ao $1^{\circ}$ bimestre letivo de 2014.

Os documentos estudados emergem da escrita da professora titular da turma, que se utiliza dos pareceres descritivos com vistas a efetuar a tarefa da avaliação. Como base em nossa perspectiva teórica, temos compreendido que ao emitir o parecer sobre o aluno, o docente também se descreve e se inscreve no documento por meio de suas narrativas. Um modo de ser docente que ao escrever utiliza seus múltiplos "eus". A fabricação desses documentos através das impressões avaliativas, constitui-se por meio de padrões narrados e que ao mesmo tempo constituem modos de ser docente e 
modos de ser aluno. Anunciamos o poder deste dispositivo, emanado desde a fala de quem diz por si e das possibilidades de inventar quem ou o que é dito.

Padrões e repetições podem ser aludidos nos pareceres referentes ao $1^{\circ}$ bimestre letivo de 2014, destacados nos excertos a seguir:

Ótima aluna, procura realizar tudo que é proposto com empenho e dedicação[...] (parecer da aluna A1); Boa aluna, gosta de ouvir história, procura realizar o que é proposto, [...] (parecer da aluna A2); Bom aluno, esforçado, realiza tudo que é proposto de maneira organizada e dedicada, preocupa-se em fazer as atividades de maneira correta (parecer do aluno B1); O aluno procura realizar o que é proposto, é esforçado, dedicado, [...] (parecer do aluno B2); Ótimo aluno, dedicado. Interessado, participativo, educado, realiza tudo que é proposto com dedicação e empenho (parecer do aluno B3); Bom aluno, dedicado, interessado, participativo, realiza tudo que é proposto com dedicação e empenho (parecer do aluno B4); O aluno procura realizar o que é solicitado (parecer do aluno B5); Aluno muito dedicado, interessado, procura realizar tudo que é proposto, quando não sabe solicita auxílio da profe ou de colegas próximos [...] (parecer do aluno B6).

Com base nesses excertos, percebemos que o padrão cultural e comportamental inscrito e prescrito como o correto a seguir é de um aluno/a dedicado, esforçado e que realiza todas as atividades propostas. Alunos considerados bons ou ótimos. Qualidade a ser almejada e que se inscreve no currículo escolar por meios das prescrições. Ao prescrever o que deve ser alcançando, o docente elege critérios que lhe são favoráveis a aprendizagem do aluno. Esses critérios são escolhidos ao acaso, mas circulam em documentos, textos e leis que regem a educação, ou seja, que estão na ordem do discurso. O professor escreve e inscreve a docência posta em ação no currículo escolar. O comportamento almejado e posto em funcionamento pela docência se inscreve e prescreve padrões. Não temos por objetivo aqui, jugar a avaliação realizada pela professora titular da turma, mas sim problematizar as questões culturais que estão implicadas nesse processo de escrita.

No que remete aos conteúdos a serem alcançados, foi possível perceber o destaque dado a conhecimento por parte dos alunos em relação as Língua Portuguesa e Matemática. Como podemos perceber nos excertos a seguir, organizados em dois tópicos:

-LETRAS: Quanto à aprendizagem a aluna reconhece todas as letras do alfabeto, diferencia vogais das demais letras, já consegue ler e escrever corretamente palavras com sílabas simples e até mesmo palavras com silabas complexas tais como: Ih, $\mathrm{nh}$, ch, qu, [...] (parecer da aluna A1); Quanto a aprendizagem a aluna reconhece vogais, [...] mas no momento a aluna apresenta dificuldade para reconhecer todas as letras do alfabeto, [...] (parecer da aluna A2); O aluno conhece todas as letras do alfabeto, diferencia as vogais das demais letras, escreve corretamente e lê palavras com sílabas simples [...] (parecer do aluno B1); aluno reconhece o alfabeto, diferencia vogais das demais letras, percebe que as palavras tem sílabas, contando corretamente o número de sílabas nas palavras, já consegue escrever corretamente algumas palavras com sílabas simples (parecer do aluno B2); O aluno reconhece todas letras do alfabeto, diferencia vogais das demais letras, reconhece que as palavras tem sílabas e as conta separando-as corretamente, escreve sem omissão de letras palavras compostas por sílabas simples e complexas (parecer do aluno B3); aluno reconhece todas as letras do alfabeto, diferencia vogais das demais letras, reconhece que as palavras tem sílabas e as conta separando-as corretamente, escreve sem omissão de letras palavras compostas por sílabas simples e complexas (parecer do aluno B4); reconhece as letras do alfabeto, diferenciando as vogais, percebe que as palavras tem sílabas, contando-as corretamente, mas ao escrevê-las para separar as sílabas ainda não consegue sem o auxílio da professora ou de colegas (parecer do aluno B5); reconhece todas as letras do alfabeto, diferenciando vogais das demais letras, percebe que as palavras são formadas 
por sílabas e consegue separá-las de maneira correta oralmente, e na escrita separa corretamente as compostas por sílabas simples (parecer do aluno B6).

-NÚMEROS: Reconhece números além de 10 e os relaciona as suas quantidades, realiza pequenos cálculos envolvendo adição e subtração (continhas de mais e de menos) (parecer da aluna A1); reconhece alguns números entre o 0 e 10 e os relaciona as suas quantidades (parecer da aluna A2); reconhece números além do 10 e os relaciona as suas quantidades, realiza corretamente continhas envolvendo adição e subtração (mais e menos) (parecer do aluno B1); apresenta dificuldade para [...], realizar cálculos, ou seja, continhas de adição e subtração (mais e menos), reconhecer e escrever números de maneira ordenada além de 20 (parecer do aluno B2); Quanto aos conhecimentos matemáticos, conta oralmente, escreve e reconhece números além do 50, realiza continhas envolvendo adição e subtração(mais e menos) (parecer do aluno B3); Quanto aos conhecimentos matemáticos, conta oralmente, escreve e reconhece números além do 50, realiza continhas envolvendo adição e subtração(mais e menos) (parecer do aluno B4); conta de maneira ordenada e reconhece números além do 10, realiza corretamente continhas de adição(mais), no momento apresenta dificuldade para realizar continhas envolvendo subtração(menos)(parecer do aluno B5); nas atividades envolvendo conhecimentos matemáticos o aluno conta oralmente além do 10, já consegue realizar algumas continhas de adição(mais), mas no momento não compreendeu os cálculos envolvendo subtração(continhas de menos) (parecer do aluno B6).

Ao eleger os conhecimentos referentes aos componentes Língua Portuguesa e Matemática, se elege também o conhecimento a ser avaliado e o conhecimento desconsiderado no processo avaliativo. Como é possível observar nos excertos acima, os conhecimentos referentes a letras e números são mencionados nos oito pareceres. Além da Matemática e da Língua Portuguesa, a Educação Física também é descrita como conhecimento avaliado, entretanto os conhecimentos referentes aos demais componentes curriculares não são citados ou avaliados nos pareceres. Ao escrever os conhecimentos a serem avaliados ou não, o professor também inscreve o que perpassa pela ordem do discurso escolar. Suas escritas estão implicadas em leis, formações continuadas, práticas que o fazem docente desses conhecimentos, que os impulsionam a pensar diariamente na aprendizagem dos números e letras por parte dos seus alunos.

Sustentamos que metodologicamente estes pareceres poderiam ser trazidos em sua íntegra, (e de todo o ano letivo), entretanto devido à extensão permitida para a escrita desse artigo optamos apenas pelos excertos. A elaboração de parecer descritivo seria uma maneira de dizer, desdizer ou não dizer que o aluno estaria ou não apto a cursar o ano/série seguinte estando ou não habilitado? Os termos usados são padronizados? Parece haver uma forma quase universal de descrever, de narrar os sujeitos, quando a escola parece querer ou necessita formatar o sujeito de acordo com as necessidades do mercado e com as normas da sociedade, para que ele além de ser produtivo e ajude na manutenção econômica, também por outro lado, não contribua para a sua desorganização, quando há, por exemplo, a indicação de um comportamento para o ajuste à normalidade 'necessária' para viver em sociedade e produzir, como é possível destacar nos excertos a seguir:

Quanto ao comportamento, em alguns momentos apresenta-se bastante teimosa, negando-se a copiar e realizar o que é solicitado, o qual também ocorre nas aulas de educação física (parecer da aluna A2). No momento precisa melhorar quanto a atitudes e comportamentos de desrespeito e agressividade, pois frequentemente envolve-se em desentendimentos com colegas. Sugestão: aproveitar seu potencial e capacidade de aprender e ler muito em casa, melhorar as atitudes e comportamento no relacionamento com todos (parecer do aluno B4). Quanto ao comportamento o aluno relaciona-se bem com todos, mas percebe-se que o aluno apresenta-se bastante distraído, às vezes alheio às atividades propostas em aula, normalmente não participa de comentários e debates sobre conteúdos trabalhados, tais como histórias e relatos, o qual se faz necessário 
insistir para que participe (parecer do aluno B5); Quanto ao comportamento é um aluno que gosta de auxiliar colegas e professores, mas frequentemente envolve-se em desentendimentos com colegas. Sugestão: Melhorara comportamento e relacionamento com colegas, realizar os temas solicitados (parecer do aluno B6).

Tais pareceres descritivos nos oportunizaram uma sensação de incompletude e por isso escolhemos falar sobre eles (ou fomos escolhidos por eles). Uma (i)lógica incompletude nossa (por isso nos constituímos pesquisadores), que nos levam à dos pareceres (também não são?). Incompletude que pode ser descompleta e que problematizamos em vez de normalizá-la, o que também não se constitui como um fator de impedimento. Em nenhum momento buscamos um instrumento de avaliação completo. Incursionamos em trabalhos, como os de Fröhlich (2010) e Sarturi (2013), que tratam deste assunto em um determinado lugar e tempo, e que nos mostram discursos curriculares como componentes indissociáveis junto à educação.

Agora sabemos do que e como eles falam. Pensamos. Será que já foi dito tudo? Ou o mais importante? Se o que foi dito não esgotou, pelo menos dissecou a quase totalidade através da capacidade argumentativa de tais estudiosos. Sobrou algo para dizermos? Os pareceres vistos em nossa escola nos dizem algo que não pensamos em falar e que ainda não foi dito? Em busca desse algo a ser dito, precisamos nos posicionar.

Pensamos ser preciso, estrategicamente, em algum momento, fabricar pareceres para, 'sendo' pareceristas, podermos 'viver' um parecer. A todo o momento precisamos de um 'conversar' sobre o tema, para um direcionamento do caminhar. Onde está a censura no parecer? O que o este documento omite? O parecer omite o que o parecerista não sabe, não conhece ou não sabe como dizer. Ou não se apercebe. Não está no seu alcance cultural. Na sua capacidade discursiva. No modus operandi de quem vê e diz ou que precisa dizer. Na sua vontade de dizer ou não, mesmo que tenha visto.

No caso de um parecer descritivo de um aluno, é preciso a percepção acerca da vontade, do interesse do leitor. Não escrever o que o leitor quer ler, mas sobre o que ele deseja ler. O que pode ser de interesse do destinatário o qual interessa saber. Há uma tradição cultural dominante na fabricação de pareceres? Quais agentes ou fatores são mais determinantes ou modeladores para a feitura do parecer? Se os pareceres estão cada vez mais em evidência, é de se pensar que estão, por isso, assumindo um grau maior de interferência e importância no sistema educacional, o que pode levar a ser visto com foco mais nítido, mais direcionado.

Durante uma reunião com professoras, colegas de trabalho, nas séries iniciais, experientes na função. Ouvimos de uma delas: (- Já trabalhei com pareceres descritivos, mas sempre colocava uma nota junto, para os pais). Não se sustenta a presença de um professor em um lugar onde não haja a possibilidade de que ele aprenda algo. Pensamos. Aprendemos. Ler e discutir o que outros dizem, tem um grau de facilidade. Pensar, refletir e, portanto, criar o que dizer, tem outro tanto de grau de dificuldade. As opiniões estão para serem contestadas, escovadas. Pensamos explorar os sentidos do termo 'parecer' na tentativa de, ao buscar em diversos dicionários (encontrados na escola), a possibilidade de multiplicação de percepções.

Aliás, qual a palavra que tem um só sentido? Em uma ida à biblioteca da escola, encontramos vinte e cinco dicionários, de vários autores e editoras ou até mesmo com recorrências daqueles ou destas, mas decidimos utilizar os que trouxessem, no mesmo livro, os dois termos do nosso interesse: 'parecer' e 'avaliar'. Acreditarmos que estes termos trazem uma conversa entre si que é incontornável, para este momento, neste trabalho. Foi um começo. Observando este critério (precisamos tê-lo), restaram selecionados vinte dicionários, dos quais providenciamos cópias das páginas onde constava nosso interesse, para comodidade do manuseio e leitura visando à análise. Documentos para ajudarem na leitura de outros. Braga diz que avaliar é um verbo transitivo direto e que: 


\begin{abstract}
1. Avaliar algo é dar uma opinião sobre ele. Os deputados avaliaram a decisão como positiva. 2. Avaliar também é estudar algo com cuidado. Avalie cada sentença e escreva $V$ diante das verdadeiras. 3 . Você avalia uma coisa quando determina qual é o seu valor, muitas vezes usando números para expressá-lo. Avaliaram a casa em cem mil reais. 4. Avaliar uma pessoa é julgar coisas como os seus conhecimentos, o seu comportamento ou as suas habilidades. Para avaliar os alunos, eu observo a participação deles nas discussões. (BRAGA; MAGALHÃES, 2011, p. 49, grifo do autor).
\end{abstract}

Para a palavra 'parecer' encontramos as definições que dizem ser, de maneira geral: um tipo de documento, relatório que traz a impressão ou manifesto de juízo, sugestão, conselho, opinião fundamentada de perito, especialista técnico ou autoridade sobre dado assunto. Abordamos os pareceres descritivos, numa perspectiva de como essa técnica influencia no controle e acompanhamento, ao nomear o aluno através de relato de seu aproveitamento na escola. Avaliação esta, que hipoteticamente remete a um aparelho de hierarquização que atua qualitativa e quantitativamente (através da nomeação que, por vezes, se utiliza de números para indicar nível de aprendizagem), procurando identificar as diferenças que ora se apresentam em uma classe heterogênea (qual não é?) de indivíduos estudantes. Este relatório individualizado é passível de observação de como se dá a narrativa que descreve o aluno/sujeito em seus aspectos mais peculiares e constitutivos, aliados ao diagnóstico da possível 'progressão' do aprendizado, ou melhor, de uma padronização a ser alcançada.

\title{
5 'PARECER' FINAL
}

Dada a importância da avaliação para o processo educacional e a recorrência do uso de instrumentos como os pareceres descritivos para esse processo, inquirimos os aspectos que nos possibilitaram os discursos que embasam a elaboração desses pareceres e que consequentemente são responsáveis pelo seu produto final: o parecer que diz o aluno aos pais e ao sistema de controle em geral, numa perspectiva que, supomos, os pareceres descritivos teriam a característica de flexibilização do diagnóstico, visto que não delineiam ou não usam um parâmetro fixo para, quantitativamente, atuarem. Entretanto, essa flexibilização da avaliação por meio da escrita segue padrões e normas culturais implicados no currículo escolar. Como é possível perceber nas continuidades e repetições expostas nos excertos referentes à avaliação do primeiro bimestres. Nesses pareceres, são eleitos conteúdos 'válidos' ou considerados de 'maior valia' e são definidos padrões comportamentais a serem seguidos para alcançá-los. Nesse aspecto, se inscreve também um modo de ser docente e sua atuação no currículo escolar.

Vimos nos pareceres descritivos, um artefato cultural que incute normas, padrões e valores culturais, isto é, modos de ensinar e possibilidades de aprendizagem em suas diversas constituições (HALL, 1997a). Uma professora prescrevendo o aluno na ordem do discurso educacional em pauta.

Quando, um dia, no horário de recreio, na sala de professores, após alguns comentários sobre entrega de boletins e pareceres, alguém disse: - Parecer descritivo não é avaliação! Seguiu-se um silêncio geral e todas se olharam. Estávamos no caminho de um tema potente. Válido. Contributivo. Fez-se preciso conversar, recortar, definir espaço de atuação e analisar flexibilizadamente o discurso contido no âmago das narrativas (re)produzidas nos pareceres descritivos. Um caminho metodológico possível, um modo de conceber o encontro entre pesquisador e objeto de estudo; sabendo que um método não é um caminho para saber sobre as coisas do mundo, mas um modo de pensamento que se desdobra acerca delas e que as toma como testemunhos de uma questão.

Quando nos propusemos a conhecer, analisar a constituição, a feitura, a fabricação de pareceres descritivos que "formatam o sujeito" (FRÖHLICH, 2010, p. 74), supomos 
ali uma ferramenta cultural de relato dos resultados de uma gama de percepções a serviço da maquinaria a que serve a avaliação no contexto educacional. Vimos que esta ferramenta, mesmo que tenha uma abrangência temporal, uma vez que fala do aluno a cada período bimestral, também pode se valer de construções mais imediatistas, como os portfólios, que são construídos no dia a dia ou de diários de bordo que podem contribuir como peças estratégicas na construção dessa avaliação. Assim, como para sua constituição e constante reconstituição estratégica exigida pela pedagogia atual, ante os entes culturais envolvidos e que constituem a escola de hoje.

Percebemos estar prestes a, metodologicamente, elaborar um parecer descritivo acerca de pareceres descritivos. Esta escrita se constitui de uma maneira que, falando de parecer descritivo, ela também o é (ou pode ser). Buscamos pensar novas possibilidades e, assim, termos novos saberes acerca deles. E eles já não serão mais os mesmos. Nem nós. Não se trata do estabelecimento de dicotomias, de ser contra ou a favor de pareceres descritivos, mas de vê-los como artefatos que produzem narrativas e ao mesmo tempo são produzidas por elas.

O professor é, na medida do possível, um arrazoado inventor de opiniões, em especial através da linguagem. As que emitem, ressonam, reverberam desde seus estudos, pesquisas, vivências, práticas em ambiente escolar. Queremos também trazer a ideia de que a docente que elabora tais pareceres, até então, sequer suspeita ser vista. Parece não haver, na sua fala, de que ela tenha aspirado estar ali. Mas, seus movimentos lhe anunciam. É crível supor, portanto nomear isso e, assim, fazer existir. Ela se desloca no texto, caminha. Parecer descritivo serve também para não servir para nada quando se presta a servir para tudo, quando é usado para substituir a avaliação em situações que os alunos não restarão retidos no ano letivo de curso, independentemente do desempenho escolar. Até quando?

Acreditamos com isso, que estivemos mais perto dos riscos, conseguimos de certa maneira trazer nossa própria opinião e a tenhamos fundamentado originalmente desde nosso "ser professor". Afinal, para que pode ter servido os ensinamentos e apontamentos de nossos professores (e demais púlpitos do caminho), senão para que tenhamos construído nossas provisórias verdades a serem compartilhadas para a discussão? Assim, esta pesquisa experimentou várias idas e vindas (e inércias). Reviravoltas, também oniformes.

O parecer esteve sempre caminhando conosco (será?), com tudo que nos dizia. Nos fez descobrir os não-cobertos. Revisitamos quem não conhecíamos. Chegamos por caminhos não caminhados. Caminhamos do lugar-comum ao sem-lugar. Nossa pesquisa esteve amparada pelo desamparo calculado, típico, próprio dos Estudos Culturais e que de alguma maneira oportunizou certa desnaturalização acerca de nossas maneiras de ver, de dizer a educação, ante a dinamicidade da vida escolar de um aluno, relatada em multiplicidades de aspectos, recorrências de acontecimentos, apontamentos de faltas e déficits, carências em relação às metas a serem atingidas (ou seus antagônicos). Foi desde a docência, atravessada pelo currículo, em chão de escola, que resolvemos tentar ver quem diz tudo isso e iluminar cientificamente a possibilidade da constituição do docente que empresta de si, da sua invenção particular, que constitui e aponta uma invenção do outro e segue permanentemente se reinventando.

Assim, compreendemos os pareceres descritivos no que tange ao seu processo social de produção cultural como artefatos culturais. Logo, a docente ao escrever os pareceres analisados nesse trabalho, também estava descobrindo-se, na sua narrativa de quem, mesmo sem essa intenção, também inventa a si ao olhar e dizer o seu aluno na avaliação escolar. Proporcionando, portanto, pensarmos a partir de um movimento que entende a linguagem narrativa utilizada em pareceres descritivos, não apenas como representativa, mas como constitutiva da realidade descrita. Nessa esteira do pensamento, inferimos que o professor, ao emitir seu conhecimento a respeito do aluno, posicionando-o, nomeando-o, também está se anunciando no parecer. Logo, o professor, ao escrever pareceres descritivos, também se 'inscreve' neles. 


\section{REFERÊNCIAS}

BAUMAN, Z. Vidas desperdiçadas. Revista de Ciências Sociais, Rio de Janeiro, n. 23, p. 145152, nov. 2005. Disponível em: <http://periodicos.ufpb.br/index.php/politicaetrabalho/article/ view/6582/4139>. Acesso em: 20 fev. 2016.

BRAGA, R. C. E.; MAGALHÃES, M. A. F. Fala Brasil!: dicionário ilustrado da língua portuguesa. Belo Horizonte: Dimensão, 2011.

CORAZZA, S. M. Currículo e política cultural da avaliação. Educação e Realidade, Porto Alegre, v. 20, n. 2, p. 47-59, 1995.

Labirintos da pesquisa, diante dos ferrolhos. In: COSTA, M. V. (Org.). Caminhos investigativos: novos olhares na pesquisa em educação. 2. ed. Rio de Janeiro: DP\&A, 2002. p. 105-131.

COSTA, M. V.; SILVEIRA, R. M. H.; SOMMER, L. H. Estudos culturais, educação e pedagogia. Revista Brasileira de Educação, Campinas, n. 23, p. 36-61, 2003. Disponível em: <http://www. scielo.br/pdf/rbedu/n23/n23a03>. Acesso em: 10 mar. 2016.

FABRIS, E. T. H. A escola contemporânea: um espaço de convivência? In: REUNIÃO ANUAL DA ANPED, 30., 2007, Caxambu. Anais... Rio de Janeiro: ANPED, 2007. Disponível em: <http://30reuniao.anped.org.br/trabalhos/GT13-3044--Int.pdf>. Acesso em: 20 fev. 2016.

FABRIS, E. T. H.; SILVA, R. R. D. Análise de uma matriz pedagógica escolar: a invenção da docência e de pessoas em uma escola de periferia. Currículo sem Fronteiras, v. 15, n. 2, p. 492-507, maio/ago. 2015.

FÉLIX, J. Entrevistas on-line ou algumas pistas de como utilizar bate-papos virtuais em pesquisas na Educação e na Saúde. In: MEYER, D. E. E.; PARAÍSO, M. A. (Org.). Metodologias de pesquisas pós-críticas em educação. 2. ed. Belo Horizonte: Mazza, 2014. p. 181-206.

FLICK, U. Introdução à pesquisa qualitativa. 3. ed. Porto Alegre: Artmed, 2009.

FOUCAULT, M. A ordem do discurso. 4. ed. São Paulo: Edições Loyola, 1998.

FRÖHLICH, R. Avaliação e pareceres descritivos: a (des)construção do "sujeito - aluno especial". 2010. 128 f. Dissertação (Mestrado em Educação)- Universidade de Santa Cruz do Sul, Santa Cruz do Sul, 2010.

GUSTSACK, F. Elogios da linguagem: perturbações na formação de professores. In: SEMINÁRIO DE PESQUISA EM EDUCAÇÃO DA REGIÃO SUL, 7., 2008, Itajaí. Anais... Itajaí-SC: UNIVALI, 2008. Disponível em: <https://slidex.tips/download/elogios-da-linguagemperturbaoes-na-formaao-de-professores-gustsack>. Acesso em: 23 mar. 2018.

HALL, S. A centralidade da cultura: notas sobre as revoluções culturais do nosso tempo. Educação \& Realidade, Porto Alegre, v. 22, n. 2, p. 40-41, jul./dez. 1997a.

HALL, S. The work of representation. In:

(Org.). Representation: cultural representations and signifying practices. London: $\overline{\text { Sage, } 1997 b . ~ p . ~ 1-78 . ~}$

HILLESHEIM, B. Lições de infância para a prática da pesquisa. In: OLIVEIRA, C. J.; HILLESHEIM, B.; SILVA, M. L. (Org.). Estudos culturais, educação e alteridade. Santa Cruz do Sul: EDUNISC, 2009. p. 239-256.

HOFFMANN, J. O jogo do contrário em avaliação. Porto Alegre: Mediação, 2009. 
LARROSA, J. A arte da conversa. In: SKLIAR, C. Pedagogia (improvável) da diferença: e se o outro não estivesse aí? Rio de Janeiro: Dp\&a, 2003. p. 211-216.

. Notas sobre a experiência e o saber da experiência. Revista Brasileira de Educação, Rio de Janeiro, n. 19, p. 20-28, jan./abr. 2002.

Tremores: escritos sobre experiência. Belo Horizonte: Autêntica, 2015.

LUCKESI, C. C. Avaliação da aprendizagem na escola e a questão das representações sociais. Eccos Revista Científica, São Paulo, v. 4, n. 2, p. 79-88, 2002.

MASSCHELEIN, J. Filosofia como (auto)educação: para fazer a voz do pedagogo ser ouvida. In: MASSCHELEIN, J.; SIMONS, M. A pedagogia, a democracia, a escola. Belo Horizonte: Autêntica, 2014. p. 9-26.

OLIVEIRA, C. J. Formação docente na revista Nova Escola. In: OLIVEIRA, C. J.; HILLESHEIM, B.; SILVA, M. L. (Org.). Estudos culturais, educação e alteridade. Santa Cruz do Sul: EDUNISC, 2009. p. 178-198.

Práticas etnomatemáticas no cotidiano escolar: possibilidades e limitações. In: KNIJNIK, G.; WNDERER, F.; OLIVEIRA, C. J. (Org.). Etnomatemática, currículo e formação de professores. 2. ed. Santa Cruz do Sul: EDUNISC, 2010. p. 239-252.

PARAISO, M. A. Metodologias de pesquisa pós-críticas em educação e currículo: trajetórias, pressupostos, procedimentos e estratégias analíticas. In: MEYER, D. E.; PARAISO, M. A. (Org.). Metodologias de pesquisas pós-críticas em educação. 2. ed. Belo Horizonte: Mazza, 2014. p. 25-48.

PEREIRA, M. V. A escrita acadêmica: do excessivo ao razoável. Revista Brasileira de Educação, Rio de Janeiro, v. 18, p. 213-244, 2013.

SARTURI, C. A. Cultura e identidade surda no discurso curricular e seus efeitos na docência de professores formados no curso de Letras/Libras. 2013. 91 f. Dissertação (Mestrado em Educação)- Universidade Federal de Santa Maria, Santa Maria, 2013.

SILVA, M. L. História \& cotidiano: 101 textos para pensar o mundo atual. Santa Cruz do Sul: Gazeta Santa Cruz, 2014.

Apresentação. In: OLIVEIRA, C. J.; HILLESHEIM, B.; SILVA, M. L. (Org.). Estudos culturais, educação e alteridade. Santa Cruz do Sul: EDUNISC, 2009. p. 7-8.

SILVA, T. T. Teoria cultural e educação: um vocabulário crítico. Belo Horizonte: Autêntica, 2000.

THOMA, A. S. Identidades e diferença surda constituídas pela avaliação. In: THOMA, A. S.; KLEIN, M. Currículo e avaliação: a diferença surda na escola. Santa Cruz do Sul: EDUNISC, 2009. p. 16-31.

VEIGA, I. P. Projeto político-pedagógico da escola: uma construção coletiva. In:

(Org.). Projeto político-pedagógico da escola: uma construção possível. Campinas: $\overline{\text { Papirus, }}$ 1998. p. 11-35.

VEIGA-NETO, A. É preciso ir aos porões. Revista Brasileira de Educação, Rio de Janeiro, v. 17, n. 50, maio/ago. 2012.

WORDLE-CREATE. Aplicação web wordle. [201-]. Disponível em: <http://www.wordle.net/ create>. Acesso em: 18 jan. 2016. 